\title{
Effects of High-Flow Nasal Cannula on End-Expiratory Lung Impedance in Semi-Seated Healthy Subjects
}

\author{
Gustavo A Plotnikow PT, Arnaud W Thille MD PhD, Daniela N Vasquez MD, \\ Romina A Pratto PT, Corina M Quiroga PT, María E Andrich PT, Javier H Dorado PT, \\ Ramiro S Gomez PT, Pablo A D’Annunzio PT, José L Scapellato MD, and Dante Intile MD
}

BACKGROUND: High-flow nasal cannula (HFNC) enables delivery of humidified gas at high flow while controlling the $\mathrm{F}_{\mathrm{IO}_{2}}$. Although its use is growing in patients with acute respiratory failure, little is known about the impact of HFNC on lung volume. Therefore, we aimed to assess lung volume changes in healthy subjects at different flows and positions. METHODS: This was a prospective physiological study performed in $\mathbf{1 6}$ healthy subjects. The changes in lung volumes were assessed by measuring end-expiratory lung impedance by using electrical impedance tomography. All the subjects successively breathed during $5 \mathrm{~min}$ in these following conditions: while in a supine position without HFNC (T0) and 3 measurements in a semi-seated position at $45^{\circ}$ without $\mathrm{HFNC}$ (T1), and with HFNC at a flow of $30 \mathrm{~L} / \mathrm{min}$ (T2), and $50 \mathrm{~L} / \mathrm{min}$ (T3). RESULTS: Compared with the supine position, the values of end-expiratory lung impedance significantly increased with the subjects in a semi-seated position. End-expiratory lung impedance significantly increased after HFNC initiation in subjects in a semi-seated position and further increased by increasing flow at $50 \mathrm{~L} / \mathrm{min}$. When taking the end-expiratory lung impedance measurement in subjects in a semiseated position (T1) as reference, the differences among the medians of global end-expiratory lung impedance were statistically significant $(P<.001)$, which amounted to 1.05 units in T1; 1.12 units in T2; and 1.44 units in T3 $(P<.05$ for all comparisons, Wilcoxon test $)$. The breathing frequency did not differ between the supine and semi-seated position (T0 and T1) but significantly decreased after initiation of HFNC and further decreased at high flow. T0 and T1 were not different $(P=.13)$; whereas there was a statistically significant difference among $\mathrm{T} 1$, T2, and T3 $(P<.05$, post hoc test with Bonferroni correction). CONCLUSIONS: In healthy subjects, the semi-seated position and the use of HFNC increased end-expiratory lung impedance globally. These changes were accompanied by a significant decrease in the breathing frequency. Key words: high-flow nasal cannula; oxygen inhalation therapy; high-flow devices; electrical impedance tomography; end-expiratory lung impedance; end-expiratory lung volume. [Respir Care 2018;63(8):1016-1023. (c) 2018 Daedalus Enterprises]

\section{Introduction}

Use of high-flow nasal cannula (HFNC) is a therapy that allows the delivery of heated, humidified gas at high

\footnotetext{
Mr Plotnikow, Ms Pratto, Ms Quiroga, Ms Andrich, Mr Dorado, Mr Gomez, Mr D'Annunzio are affiliated with the Division of Respiratory Care, Intensive Care Unit, Anchorena Hospital, Buenos Aires, Argentina. Dr Thille is affiliated with Centre Hospitalier Universitaire de Poitiers, INSERM CIC 1402 ALIVE, Université de Poitiers, Poitiers, France. Drs Vasquez, Scapellato, and Intile are affiliated with the Intensive Care Unit, Anchorena Hospital, Buenos Aires, Argentina.
}

flow (up to $60 \mathrm{~L} / \mathrm{min}$ ). ${ }^{1}$ Its use in ICUs has increased in the past few years due to its proven benefit in certain clinical contexts, such as acute hypoxemic respiratory failure ${ }^{2}$ and prevention of orotracheal re-intubation. ${ }^{3}$ Likewise, there is evidence of its efficacy in other pathologies that require admission to ICU, for example, respiratory failure in pa-

\footnotetext{
The authors have disclosed no conflicts of interest.

Presented by Mr Plotnikow at the 27th Argentinian Conference of Critical Care, September 2nd, 2017 Córdoba, Argentina.
} 
tients who are immunocompromised. ${ }^{4-6}$ The mechanism whereby HFNC is effective in the aforementioned situations is still under discussion; however, the presence of positive airway pressure in addition to the high flow used, 7,8 followed by an increase in lung volumes, could explain, in part, its effectiveness. ${ }^{9,10}$

Electrical impedance tomography (EIT) is a noninvasive lung impedance assessment method performed with portable equipment, at the foot end of the patient's bed, is free of radiation, and provides real-time images. ${ }^{11,12}$ Monitoring through EIT involves the application of a low electrical current and the measurement of the resulting voltages to determine impedance changes related to ventilation, especially those related to regional ventilation. It has been demonstrated that, in patients who are intubated, an adequate correlation exists between end-expiratory lung volume (EELV) and end-expiratory lung impedance. ${ }^{13,14}$ In recent years, EIT has been used to assess changes in lung volumes as a result of changes in the body position in healthy subjects. ${ }^{9,15,16}$ It has also been used to study changes in end-expiratory lung impedance related to the use of HFNC in subjects in the prone position. ${ }^{10}$ However, until now, to our knowledge, only one study assessed the impact on end-expiratory lung impedance of HFNC use at different flows and with the subject in the semi-seated position at a $45^{\circ}$ angle, although the laboratory device used for such purposes is difficult to adapt to clinical practice.

Our primary objective was to assess end-expiratory lung impedance global changes induced by HFNC use at different flows in healthy subjects and with the subjects in the semi-seated position. The secondary objectives consisted of analyzing end-expiratory lung impedance behavior in different lung zones and the impact of HFNC use on breathing frequency.

\section{Methods}

We conducted a prospective physiological study between March 13 and April 7, 2017, in the ICU of Anchorena Hospital in Buenos Aires, Argentina. The investigational review board of Anchorena Hospital reviewed and approved the study protocol.

\section{Participants}

Healthy subjects $>18$ y of age and with no smoking history were included. Each participant gave informed con-

Correspondence: Gustavo A Plotnikow PT, 1872 Tomás M de Anchorena Street, 1425 Buenos Aires, Argentina. E-mail: gplotnikow@gmail.com

DOI: $10.4187 /$ respcare. 06031

\section{QUICK LOOK}

\section{Current knowledge}

The use of the high-flow nasal cannula (HFNC) in healthy individuals and in patients with acute hypoxemic respiratory failure when in the semi-seated position has been associated with an increase in end-expiratory lung impedance and a decrease in breathing frequency.

\section{What this paper contributes to our knowledge}

The end-expiratory lung impedance increase in healthy subjects was associated with the use of HFNC and with changes in body position. There was a significant increase in end-expiratory lung impedance when the position changed from supine to sitting, but this was not accompanied by changes in breathing frequency in the subjects when breathing room air. However, the use of HFNC with the subjects in a semi-seated position was followed not only by a gain in endexpiratory lung impedance but also by a decrease in breathing frequency.

sent to be included in the study. Confidentiality of the data was preserved through the creation of a coded registration form for each participant. The name or any other information that would make it possible to identify the subject was kept strictly confidential and was not, nor will be, made public under any circumstances.

\section{Main Variables of Interest}

We gathered the participants' demographic and anthropometric data as well as their breathing frequency, changes in end-expiratory lung impedance measured through the EIT, and their parameters during the use of HFNC. For interventions and measurements, an EIT (PulmoVista 500; Dräger, Lübeck, Germany), previously calibrated and selftested according to the manufacturer's recommendations, was used, together with 16-electrode rubber belts selected in accordance with each participant's thoracic diameter. The belt was placed between the fourth and the sixth intercostal space, on the skin, which was previously wetted with liquid alcohol to improve contact of the electrodes and thereby generate an optimal signal recording. A reference gel electrode was placed on the anterior abdominal wall.

End-expiratory lung impedance measurements are regarded as a relative value, expressed in units, compared with a reference value. The global and regional end-expiratory lung impedance variation (region of interest) in 


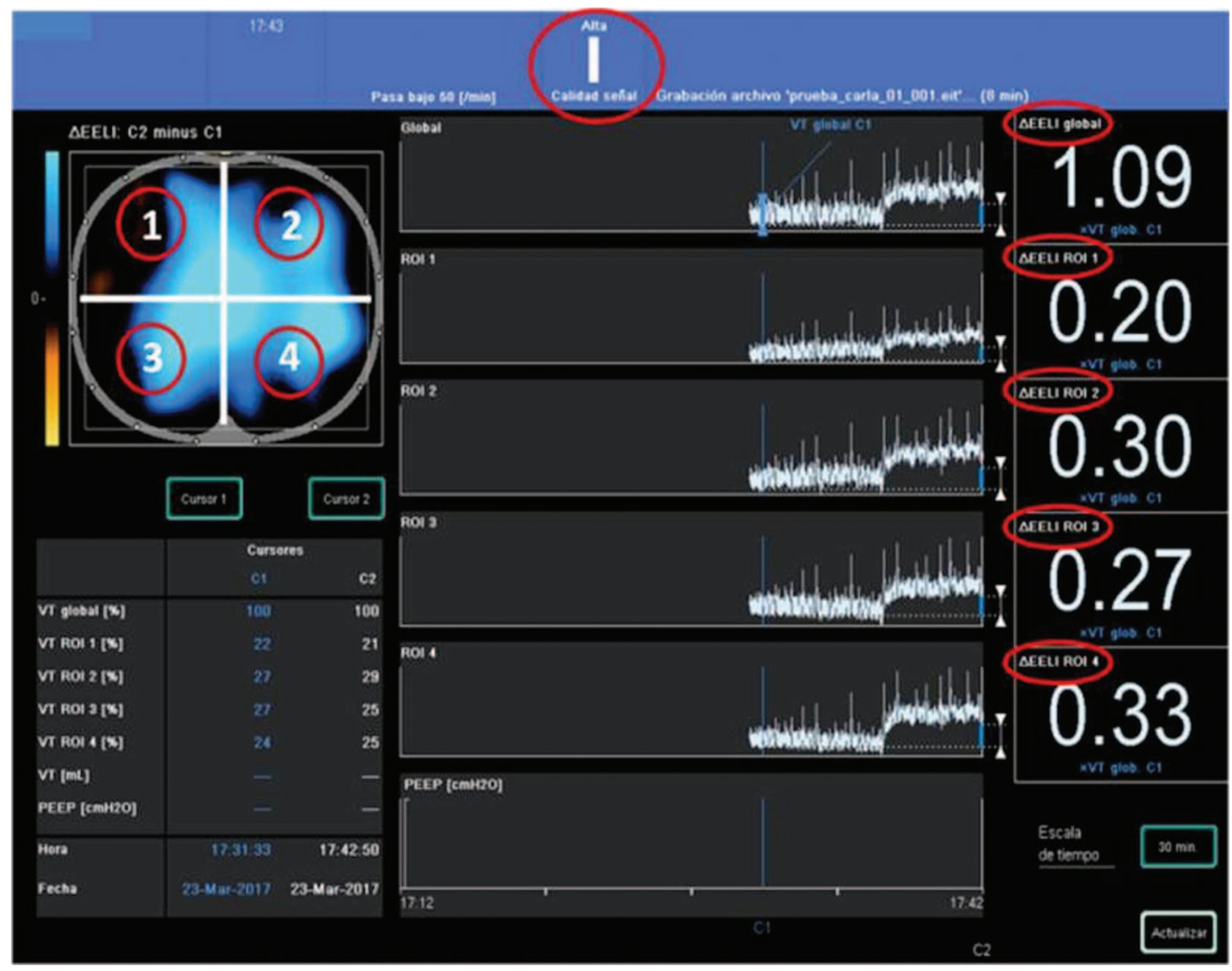

Fig. 1. The region of interest (ROI) function allows the definition of 4 regions (1, 2, 3, and 4 in the top left the figure) within the impedance image of the global end-expiratory lung impedance. For this study, with a high signal quality, 4 ROls were defined as quadrants. Were considered toghether ROI 1-2 and ROI 3-4 respectively.

different positions was recorded through the end-expiratory lung impedance. The region of interest function defines 4 sectors (1, 2, 3 and 4) (Fig. 1) within the impedance image of the global end-expiratory lung impedance. Each of these sectors inform us about the corresponding endexpiratory lung impedance variation value. Thus, the image can be divided horizontally or in quadrants. For this study, we obtained a high-quality signal and chose 4 regions of interest as quadrants. For the analysis of different regions, we considered regions of interest $1-2$ and regions of interest 3-4.

An AIRVO 2 (Fisher \& Paykel, Auckland, New Zealand), a humidifier chamber with a heated wire circuit for adults (900PT501; Fisher \& Paykel) and silicone nasal cannulae for high-flow oxygen therapy (Optiflow OPT844 medium and OPT846 large; Fisher \& Paykel) were used as a high-flow oxygen therapy device. During implementation, the flow, temperature, and $\mathrm{F}_{\mathrm{IO}_{2}}$ used were recorded.

Four lung impedance measurements were taken. One with each subject in the supine position, at an angle of $180^{\circ}$, with no HFNC (T0). Afterward, 3 measurements with the subject in a semi-seated position, at a $45^{\circ}$ angle, were taken; the first with no HFNC ( $\mathrm{T} 1$, baseline), the second with HFNC at a flow of $30 \mathrm{~L} / \mathrm{min}$ (T2), and the third with HFNC at a flow of $50 \mathrm{~L} / \mathrm{min}$ (T3). The implementation of $\mathrm{HFNC}$ was carried out with $\mathrm{F}_{\mathrm{IO}_{2}}$ of 0.21 and a temperature of $31^{\circ} \mathrm{C}$ in all the cases. The subjects remained in each of these positions for $5 \mathrm{~min}$. There was a 5-min pause between one measurement and the next, during which time the volunteer remained in a supine position, at an angle of $180^{\circ}$, and with no HFNC to rule out a sum of effects. During the study period, the subjects were asked to maintain a nasal breathing pattern, at a normal rate and with the mouth closed. The main researcher (GAP) was responsible for both handling the tomograph and implementing the protocol, whereas an assistant (RAP, CMQ, MEA, JHD, RSG, PAD) was in charge of recording the data on a paper form in real time. At the same time, each of the measurements in digital format (screenshots) was filed by means of a data storage device connected to the PulmoVista 500 tomograph's USB port. 
HFNC AND END-EXPIRATORY LUNG IMPEDANCE

Table 1. Demographic and Anthropometric Characteristics of the 16 Healthy Subjects Who Participated in the Study

\begin{tabular}{llcccc}
\hline \hline Subject No. & Sex & Age $(\mathrm{y})$ & Height $(\mathrm{cm})$ & Weight $(\mathrm{kg})$ & Body Mass Index $\left(\mathrm{kg} / \mathrm{m}^{2}\right)$ \\
\hline 1 & Male & 32 & 172 & 87 & 29.4 \\
2 & Male & 33 & 183 & 69 & 23.7 \\
3 & Female & 40 & 173 & 59 & 22.1 \\
4 & Female & 33 & 163 & 87 & 22.2 \\
5 & Male & 35 & 175 & 75 & 28.4 \\
6 & Male & 30 & 166 & 51 & 27.2 \\
7 & Female & 39 & 167 & 72 & 25.3 \\
8 & Male & 39 & 168 & 68 & 22.2 \\
9 & Female & 32 & 175 & 56 & 26 \\
10 & Female & 43 & 157 & 74 & 29.1 \\
11 & Male & 33 & 172 & 62 & 24.7 \\
12 & Female & 37 & 173 & 55 & 22.2 \\
13 & Female & 38 & 167 & 75 & 22.0 \\
14 & Female & 33 & 158 & 74 & 2.6 \\
15 & Male & 27 & 173 & & 24.7 \\
16 & Male & 29 & & & \\
\hline
\end{tabular}

\section{Statistical Analysis}

Continuous data were expressed as mean $\pm \mathrm{SD}$ or as median and interquartile range according to their frequency distribution. Categorical data were expressed as absolute values and/or percentages. The Shapiro-Wilk and the Kolmogorov-Smirnov tests of normality were conducted. To compare variables among the subjects, the non-parametric Friedman test was used for repeated measurements. Comparisons were made with the statistical Wilcoxon ranksum test with the Bonferroni correction. Analysis of variance was conducted for repeated measures for variables with normal distribution, with post hoc contrasts with the Bonferroni correction. $P$ values $<.05$ were considered significant. SPSS version 20.0 (IBM, Armonk, NY) was used for the statistical analysis.

\section{Results}

Sixteen healthy subjects ( 8 men and 8 women), with a median (interquartile range) age of 33 (32-38) y, height of $172(166.7-173.5) \mathrm{cm}$, weight of $73(61.2-76.1) \mathrm{kg}$, and body mass index of $23.2(22.2-25.9) \mathrm{kg} / \mathrm{m}^{2}$ were studied (Table 1). All the subjects followed the instructions about preserving strict nasal breathing with the mouth closed throughout the study period. Global end-expiratory lung impedance was significantly different among all the conditions $(P<.001)$ and increased from 0 to $1.05(0.72$ 1.34) units with the subject in the semi-seated position and further increased, to $1.12(0.8-2.01)$ units and $1.44(1.05-$ 2.16) units, during HFNC at a flow of 30 and $50 \mathrm{~L} / \mathrm{min}$, respectively $(P<.05$ for all comparisons, Wilcoxon test) (Fig. 2).
In addition, we found a significant difference when comparing the regions of interest grouped as regions of interest $1-2$ versus regions of interest $3-4$ (Fig. 3) $(P<.001)$. The median (interquartile range) end-expiratory lung impedance variations were $0.2(0.11-0.34)$ units, $0.27(0.08-0.45)$ units, and $0.33(0.18-053)$ units in regions of interest $1-2$; and were $0.33(0.23-0.47)$ units, $0.39(0.24-0.64)$ units, and $0.42(0.31-0.65)$ units in regions of interest $3-4$, for T1, T2, and T3, respectively $(P<.05$ for all comparisons, Wilcoxon test) (Fig. 3). The ratio of end-expiratory lung impedance in regions of interest 1-2 and regions of interest 3-4 should ideally be 1 , which indicates a homogenous ventilation. This ratio increased from 0.6 to 0.78 with the subject in the seated position, when adding HFNC at a flow of $50 \mathrm{~L} / \mathrm{min}$.

Moreover, a statistically significant difference was found when comparing the breathing frequency among all the measurements $(P<.001$, analysis of variance). In the post hoc analysis, this difference was attributed to a breathing frequency variation among $\mathrm{T} 1(15 \pm 3.6$ breaths/min), T2 (11 \pm 3.6 breaths/min), and T3 (9 \pm 2.8 breaths $/ \mathrm{min})(P<.05$ for all comparisons, post hoc test with Bonferroni correction) (Fig. 4). On the contrary, T0 and T1 were not different (16 vs 15 breaths/min, respectively) $(P=.13)$.

\section{Discussion}

The use of the HFNC in healthy subjects was associated with a significant increase in end-expiratory lung impedance, a decrease in breathing frequency, and a more uniform distribution of alveolar ventilation between lung regions. In intubated patients who are mechanically ventilated, a positive correlation has been observed be- 


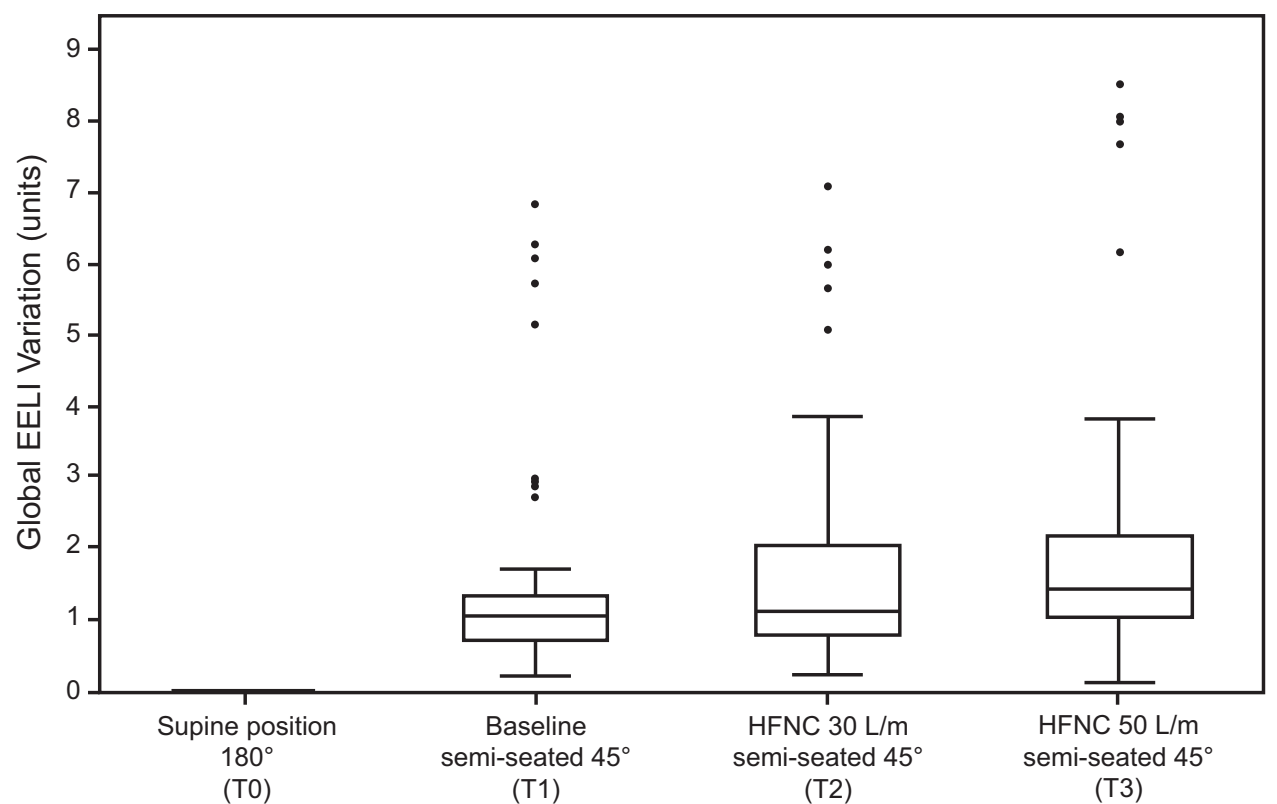

Fig. 2. Global deviation of the end-expiratory lung impedance (EELI) in the different positions according to the Friedman test $(P<.001)$. Changes between groups according to Wilcoxon test were as follows: T0 vs T1 $(P<.001)$, T0 vs T2 $(P<.001)$, T0 vs T3 $(P<.001)$, T1 vs T2 $(P=.01)$, T1 vs T3 $(P=.001)$, and T2 vs T3 $(P<.001)$. T0 $=$ supine position without HFNC; $11=$ semi-seated position at $45^{\circ}$ without HFNC (Baseline); T2 = semi-seated position at $45^{\circ}$ with HFNC at a flow of $30 \mathrm{~L} / \mathrm{m}$; T3 $=$ semi-seated position at $45^{\circ}$ with $\mathrm{HFNC}$ at a flow of $50 \mathrm{~L} / \mathrm{m} ; \mathrm{HFNC}=$ high-flow nasal cannula. Data presented as median (interquartile range).
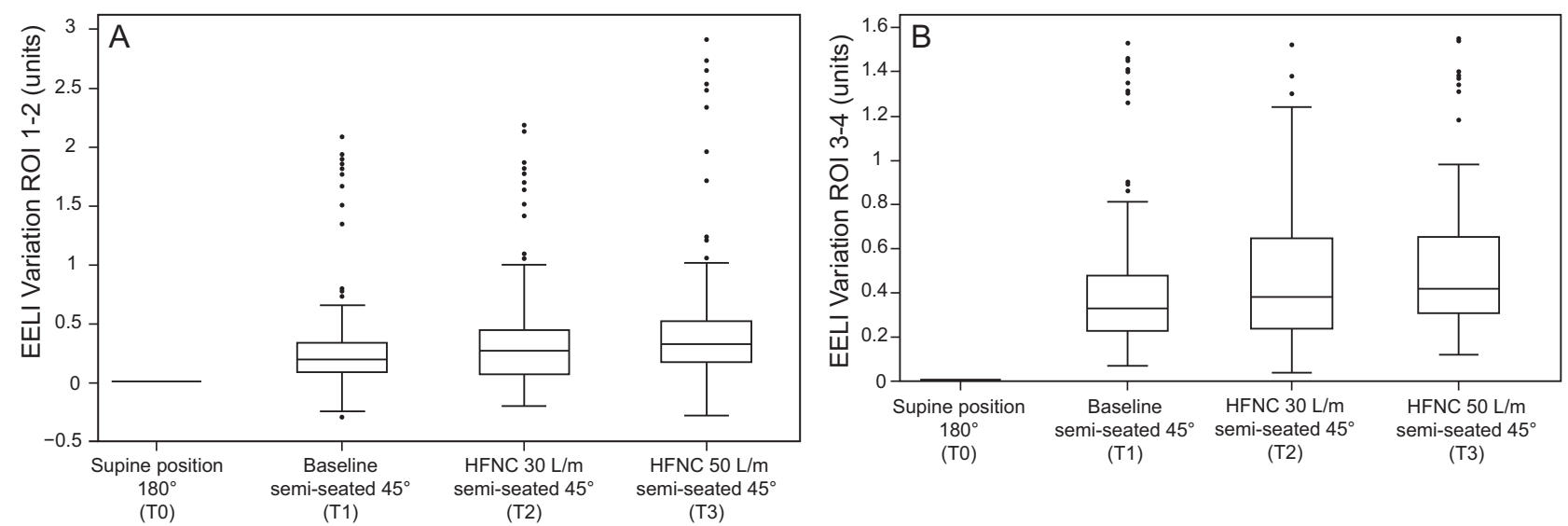

Fig. 3. Regional variation of end-expiratory lung impedance (EELI) in different positions according to the Friedman test $(P<.001)$. Changes between groups according to Wilcoxon test in regions of interest (ROI) $1-2(\mathrm{~A})$ : T0 vs T1 $(P<.001)$, T0 vs T2 $(P<.001)$, T0 vs T3 $(P<.001)$, T1 vs T2 $(P=.01)$, T1 vs T3 $(P=.001)$, and T2 vs T3 $(P=.001)$. The change in EELI variation in ROls $3-4(B)$ was as follows: T0 vs T1 $(P<.001)$, T0 vs T2 $(P<.001)$, T0 vs T3 $(P<.001)$, T1 vs T2 $(P=.01)$, T1 vs T3 $(P=.001)$, and T2 vs T3 $(P=.001)$. T0 = supine position without HFNC; T1 $=$ semi-seated position at $45^{\circ}$ without HFNC (Baseline); T2 = semi-seated position at $45^{\circ}$ with HFNC at a flow of $30 \mathrm{~L} / \mathrm{m}$; T3 = semi-seated position at $45^{\circ}$ with HFNC at a flow of $50 \mathrm{~L} / \mathrm{m}$; HFNC = high-flow nasal cannula. Data presented as median (interquartile range).

tween the end-expiratory lung impedance and the increase in EELV, ${ }^{13,17}$ which represents an important pulmonary function marker that has been suggested by some resesarchers as an alveolar recruitment tool. ${ }^{18,19}$ In this study, the use of an increasing HFNC flow in healthy subjects when in a semi-seated position at a $45^{\circ}$ angle, correlated with an increase in end-expiratory lung impedance, and, therefore, in EELV.
Corley et $\mathrm{al}^{9}$ demonstrated that the use of HFNC as opposed to a simple $\mathrm{O}_{2}$ mask in subjects with respiratory failure in the postoperative period of cardiovascular surgery was associated with an increase in global end-expiratory lung impedance. The researcher assessed the endexpiratory lung impedance with the subjects in a reverse Trendelenburg position (body supine at a $45^{\circ}$ angle) and in a seated position, at a $90^{\circ}$ angle, in an undifferentiated 


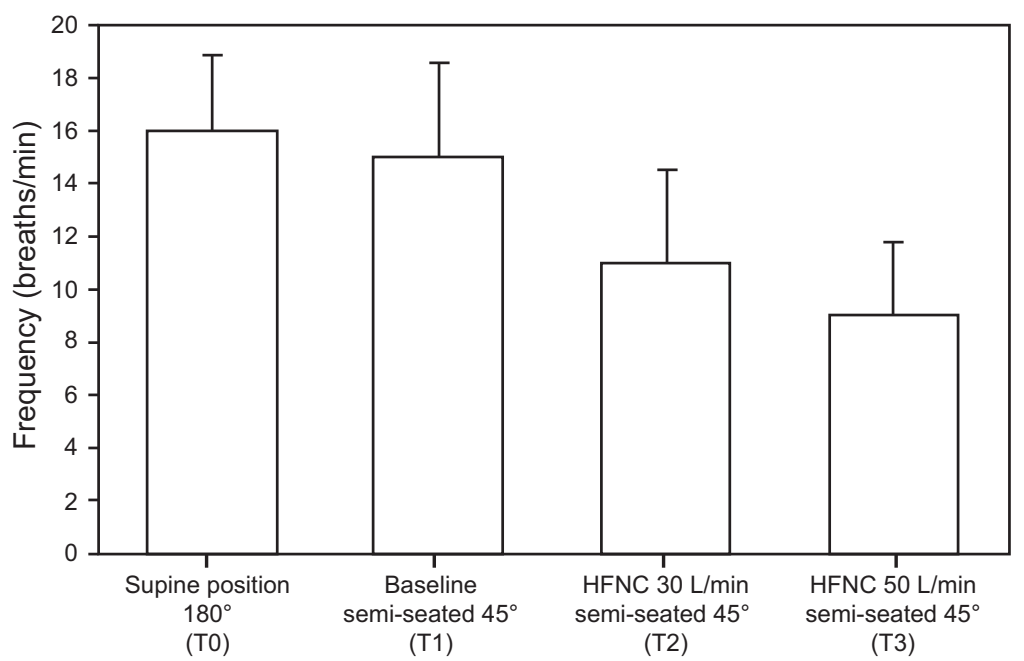

Fig. 4. The average variation of breathing frequency in different positions according to the analysis of variance $(P<.001)$. Differences between groups according to the post hoc test with the Bonferroni correction were as follows: T0 vs T1 $(P=.13)$, T0 vs T2 $(P=.02)$, T0 vs T3 $(P=.001)$, T1 vs T2 $(P=.01)$, T1 vs T3 $(P=.01)$, and T2 vs T3 $(P=.02)$. T0 $=$ supine position without HFNC; T1 $=$ semi-seated position at $45^{\circ}$ without HFNC (Baseline); T2 = semi-seated position at $45^{\circ}$ with HFNC at a flow of $30 \mathrm{~L} / \mathrm{m}$; $\mathrm{T} 3=$ semi-seated position at $45^{\circ}$ with $\mathrm{HFNC}$ at a flow of $50 \mathrm{~L} / \mathrm{m}$. Data presented as mean ( $\left.\pm \mathrm{SD}\right)$.

way; therefore, the changes in position could have determined changes in end-expiratory lung impedance, independent of those strictly generated by the use of the HFNC. Thus, in this study, it was decided that the subjects would be evaluated in a semi-seated position so as to differentiate the changes in lung volume that result from positional changes and to be able to compare the influence of HFNC. Our population of healthy subjects showed body mass index variability lower than that of the study by Corley et $\mathrm{al}^{9}$; therefore, we could consider that the effects achieved by the HFNC on end-expiratory lung impedance would apply to a more specific population. Finally, in the study by Corley et al, ${ }^{9}$ the recruited subjects had an average age higher than that of our population (65 vs $34 \mathrm{y}$ ); therefore, the age as well as the presence of comorbidities could have generated changes in ELLI independent of those caused by the use of the HFNC. Age is associated with gradual changes in pulmonary function and lung volume, ${ }^{20}$ which include an increase in lung compliance due to both the decrease in parenchymal elastic recoil and the increase in thoracic rigidity, ${ }^{21}$ which, consequently, cause changes in lung volumes. ${ }^{20,22}$

One of the research projects carried out in healthy subjects to date was that of the Spanish group Riera et al, ${ }^{10}$ who demonstrated an increase in end-expiratory lung impedance in relation to the use of HFNC among subjects who were in the supine position at an angle of $180^{\circ}$, and in the prone position. Our results were consistent with these findings, but the assessment was made with the subjects in a semi-seated position, which is the most frequently used position in spontaneously ventilated patients with acute respiratory failure. These findings were in agree- ment with Mauri et al, ${ }^{23,24}$ who demonstrated that the use of HFNC in the semi-seated position in subjects with acute hypoxemic respiratory failure improved end-expiratory lung impedance and pulmonary gas distribution. However, our study showed that this increase was not only related to the use of HFNC but also to changes in body position (Figs. 2 and 3).

As observed by other researchers, $, 910,23$ in our study, the use of the HFNC was associated with a decline in breathing frequency. Nevertheless, such a decline was more pronounced among our healthy subjects (a decrease of 4.4 and 6.3 breaths $/ \mathrm{min}$ for a flow of $30 \mathrm{~L} / \mathrm{min}$ and $50 \mathrm{~L} / \mathrm{min}$, respectively) compared with the subjects evaluated by Mauri et $\mathrm{al}^{23}$ ( 2 breaths), Corley et al ${ }^{9}$ ( 3.4 breaths), or Riera et $\mathrm{al}^{10}$ ( 2.7 breaths). The subjects included in the studies by Mauri et $\mathrm{al}^{23}$ and Corley et $\mathrm{al}^{9}$ presented with acute respiratory failure; thus, the breathing frequency decline could have been secondary to the oxygen therapy itself rather than just to the use of high $\mathrm{O}_{2}$ flow. However, the healthy subjects of our study were subjected to a $\mathrm{F}_{\mathrm{IO}_{2}}$ of 0.21 , which rules out the depressing effect $\mathrm{O}_{2}$ has on breathing frequency when acting on peripheral chemoreceptors. ${ }^{25}$ Furthermore, Parke et $\mathrm{al}^{26}$ described a significant decrease in breathing frequency among subjects when using HFNC at a flow of $30 \mathrm{~L} / \mathrm{min}$ compared with semi-seated subjects with no HFNC; however, unlike our findings, the influence of the position on end-expiratory lung impedance was not considered, no differences existed in relation to the flow applied, and an unconventional device at unusual flows (up to $100 \mathrm{~L} / \mathrm{min}$ ) was used. 
The breathing frequency reduction associated with the use of the HFNC, according to Pham et al, ${ }^{27}$ could be due to an improvement in pulmonary compliance caused by the increase in EELV, which, in turn, could decrease the work of breathing and thereby decrease breathing frequency. We were not able to confirm this hypothesis because, without the use of the HFNC, the difference between EELV in subjects in the semi-seated position and in the supine position, though significant, was not accompanied by changes in breathing frequency. In addition, we found a correlation between the use of increasing flows of $\mathrm{O}_{2}$ with HFNC and a progressive decline in breathing frequency. This decrease in breathing frequency could be associated with an improvement in alveolar ventilation ${ }^{28}$ and a fall in $\mathrm{CO}_{2}$ concentration in conducting airways ${ }^{29,30}$; whereas other variables related to breathing frequency decrease in critically ill patients, such as improvement in comfort or dyspnea, ${ }^{31}$ would not be relevant factors among our healthy subjects. Another plausible explanation for the decrease in breathing frequency caused by the use of HFNC at a flow of at least $50 \mathrm{~L} / \mathrm{min}$, is the generation of some kind of inspiratory support, 7,8 which could translate into an increase of inhaled tidal volume and, consequently, a fall in breathing frequency for the same minute ventilation.

There were limitations of this study. This study was not blinded to the investigators or to the subjects, which could add bias; however, due to the study design, it was impossible to do. An assessment of end-expiratory lung impedance behavior through EIT was made in healthy subjects, which allows for a proper application of the technique that implies an adequate mouth closure and tolerance to high flows, conditions that are difficult to achieve in patients with acute respiratory failure with high ventilatory demand. Therefore, application in daily clinical practice could prove different. ${ }^{32}$ In addition, it was decided that the assessment would only include end-expiratory lung impedance changes in relation to the use of HFNC at flows of 30 and $50 \mathrm{~L} / \mathrm{min}$. Although the use of a flow different from these could have a special impact on end-expiratory lung impedance, the flow range used was the most commonly applied in usual practice. The EIT measurement technique could represent another limitation of the study because it only assessed a relatively limited surface, which related to the transverse plane in relation to where the 16-electrode rubber belt was placed. However, a good correlation was described between the EIT and other, more specific, lungvolume measurement techniques $\left(\mathrm{r}^{2}=0.92\right) .{ }^{17}$

\section{Conclusions}

In healthy subjects, the semi-seated position at a $45^{\circ}$ angle and the use of HFNC were associated with a significant increase in EELV in both lung regions, which re- sulted in a greater homogenization of alveolar ventilation. These changes were associated with the increase in the flow used and were accompanied by a significant decrease in breathing frequency. All these effects would decrease the respiratory work load through improvement of the relationship between minute and alveolar ventilation in patients with lung disease as well. More studies are needed for testing this hypothesis.

\section{REFERENCES}

1. Roca O, Hernández G, Díaz-Lobato S, Carratalá JM, Gutiérrez RM, Masclans JR; on behalf of the Spanish Multidisciplinary Group of High Flow Supportive Therapy in Adults (HiSpaFlow). Current evidence for the effectiveness of heated and humidified high flow nasal cannula supportive therapy in adult patients with respiratory failure. Crit Care 2016;20(1):109.

2. Frat JP, Thille AW, Mercat A, Girault C, Ragot S, Perbet S, et al. High-flow oxygen through nasal cannula in acute hypoxemic respiratory failure. N Engl J Med 2015;372(23):2185-2196.

3. Hernández G, Vaquero C, González P, Subira C, Frutos-Vivar F, Rialp G, et al. Effect of postextubation high-flow nasal cannula vs conventional oxygen therapy on reintubation in low-risk patients a randomized clinical trial. JAMA 2016;315(13):1354-1361.

4. Stéphan F, Barrucand B, Petit P, Rézaiguia-Delclaux S, Médard A, Delannoy B, et al. High-flow nasal oxygen vs noninvasive positive airway pressure in hypoxemic patients after cardiothoracic surgery: A randomized clinical trial. JAMA 2015;313(23):2331-2339.

5. Díaz-Lobato S, Folgado MA, Chapa A, Mayoralas Alises S. Efficacy of high-flow oxygen by nasal cannula with active humidification in a patient with acute respiratory failure of neuromuscular origin. Respir Care 2013;58(12):e164-e167.

6. Roca O, Pérez-Terán P, Masclans JR, Pérez L, Galve E, Evangelista A, et al. Patients with New York Heart Association class III heart failure may benefit with high flow nasal cannula supportive therapy: high flow nasal cannula in heart failure. J Crit Care 2013;28(5):741746.

7. Groves N, Tobin A. High flow nasal oxygen generates positive airway pressure in adult subjects. Aust Crit Care 2007;20(4):126-131.

8. Parke RL, Eccleston ML, McGuinness SP. The effects of flow on airway pressure during nasal high-flow oxygen therapy. Respir Care 2011;56(8):1151-1155.

9. Corley A, Caruana LR, Barnett AG, Tronstad O, Fraser JF. Oxygen delivery through high-flow nasal cannulae increase and-expiratory lung volume and reduce respiratory rate in post-cardiac surgical patients. Br J Anaesth 2011;107(6):998-1004.

10. Riera J, Pérez P, Cortés J, Roca O, Masclans JR, Rello J. Effect of high-flow nasal cannula and body position on end-expiratory lung volume: a cohort study using electrical impedance tomography. Respir Care 2013;58(4):589-596.

11. Costa EL, Lima RG, Amato MB. Electrical impedance tomography. Curr Opin Crit Care 2009;15(1):18-24.

12. Riera J, Riu PJ, Casan P, Masclans JR. Electrical impedance tomography in acute lung injury [in Spanish]. Med Intensiva 2011;35(8): 509-517.

13. Hinz J, Hahn G, Neumann P, Sydow M, Mohrenweiser P, Hellige G, Burchardi H. End-expiratory lung impedance change enables bedside monitoring of end-expiratory lung volume change. Intensive Care Med 2003;29(1):37-43.

14. Moerer O, Hahn G, Quintel M. Lung impedance measurements to monitor alveolar ventilation. Curr Opin Crit Care 2011;17(3):260267. 


\section{HFNC AND END-EXPIRATORY LUNG IMPEDANCE}

15. Lumb AB, Nunn JF. Respiratory function and ribcage contribution to ventilation in body positions commonly used during anesthesia. Anesth Analg 1991;73(4):422-426.

16. Riedel T, Richards T, Schibler A. The value of electrical impedance tomography in assessing the effect of body position and positive airway pressures on regional lung ventilation in spontaneously breathing subjects. Intensive Care Med 2005;31(11):1522-1528.

17. Grivans C, Lundin S, Stenqvist O, Lindgren S. Positive end-expiratory pressure-induced changes in end-expiratory lung volume measured by spirometry and electric impedance tomography. Acta Anaesthesiol Scand 2011;55:1068-1077.

18. Dambrosio M, Roupie E, Mollet JJ, Anglade MC, Vasile N, Lemaire F, Brochard L. Effects of positive end-expiratory pressure and different tidal volumes on alveolar recruitment and hyperinflation. Anesthesiology 1997;87:495-503.

19. Gattinoni L, Pelosi P, Crotti S, Valenza F. Effects of positive endexpiratory pressure on regional distribution of tidal volume and recruitment in adult respiratory distress syndrome. Am J Respir Crit Care Med 1995;151:1807-1814.

20. Zeleznik J. Normative aging of the respiratory system. Clin Geriatr Med 2003;19(1):1-18.

21. Janssens JP, Pache JC, Nicod LP. Physiological changes in respiratory function associated with ageing. Eur Respir J 1999;13(1):197205.

22. Milic-Emili J, Torchio R, D'Angelo E. Closing volume: a reappraisal (1967-2007). Eur J Appl Physiol 2007;99(6):567-583.

23. Mauri T, Turrini C, Eronia N, Grasselli G, Volta CA, Bellani G, Pesenti A. Physiologic effects of high-flow nasal cannula in acute hypoxemic respiratory failure. Am J Respir Crit Care Med 2017; 195(9):1207-1215.

24. Mauri T, Alban L, Turrini C, Cambiaghi B, Carlesso E, Taccone, et al. Optimum support by high-flow nasal cannula in acute hypoxemic respiratory failure: effects of increasing flow rates. Intensive Care Med 2017;43:1453-1463.

25. Chowdhuri S, Badr MS. Control of ventilation in health and disease. Chest 2017;151(4):917-929.

26. Parke RL, Bloch A, McGuinness SP. Effect of very-high-flow nasal therapy on airway pressure and end-expiratory lung impedance in healthy subjects. Respir Care 2015;60(10):1397-1403.

27. Pham TM, O'Malley L, Mayfield S, Martin S, Schibler A. The effect of high flow nasal cannula therapy on the work of breathing in infants with bronchiolitis. Pediatr Pulmonol 2015;50(7):713-720.

28. Itagaki T, Okuda N, Tsunano Y, Kohata H, Nakataki E, Onodera M, et al. Effect of high-flow nasal cannula on thoraco-abdominal synchrony in adult critically ill patients. Respir Care 2014;59(1):70-74.

29. Möller W, Celik G, Feng S, Bartenstein P, Meyer G, Oliver E, et al. Nasal high flow clears anatomical dead space in upper airway models. J Appl Physiol (1985) 2015;118(12):1525-1532.

30. Möller W, Feng S, Domanski U, Franke KJ, Celik G, Bartenstein P, et al. Nasal high flow reduces dead space. J Appl Physiol (1985) 2017;122(1):191-197.

31. Vargas F, Saint-Leger M, Boyer A, Bui NH, Hilbert G. Physiologic effects of high-flow nasal cannula oxygen in critical care subjects. Respir Care 2015;60(10):1369-1376.

32. Luo JC, Lu MS, Zhao ZH, Jiang W, Xu B, Weng L, et al. Positive end-expiratory pressure effect of 3 high-flow nasal cannula devices. Respir Care 2017;62(7):888-895. 